\title{
Pembentukan Cluster Objek Daya Tarik Wisata (ODTW) di Kota Yogyakarta
}

\author{
Sarita Novie Damayanti, Rimadewi Suprihardjo \\ Jurusan Perencanaan Wilayah dan Kota, Fakultas Teknik Sipil dan Perencanaan, \\ Institut Teknologi Sepuluh Nopember (ITS) \\ Jl. Arief Rahman Hakim, Surabaya 60111 Indonesia \\ e-mail: rimadewi54@yahoo.com
}

\begin{abstract}
Abstrak - Kota Yogyakarta sebagai pusat kebudayaan di Pulau Jawa memiliki potensi unsur tradisional, baik budaya maupun keramahtamahan masyarakat lokal. Hal tersebut menjadi salah satu faktor penarik wisatawan terutama wisatawan mancanegara untuk mengunjungi Kota Yogyakarta. Peningkatan kunjungan wisatawan mancanegara akan memberikan pengaruh yang signifikan terhadap peningkatan devisa Kota Yogyakarta. Di sisi lain, meskipun telah dilakukan upaya pengembangan dalam meningkatkan kunjungan wisatawan mancanegara, masih terdapat permasalahan berupa kurang meratanya distribusi wisatawan mancanegara antar ODTW di pusat dan pinggir kota, sehingga dibutuhkan integrasi ODTW sebagai bentuk pemerataan kunjungan. Artikel ini merupakan bagian dari penelitian terkait pengembangan integrasi ODTW Kota Yogyakarta, dimana artikel ini memuat proses pembentukan cluster sebagai salah satu langkah dalam meningkatkan integrasi ODTW. Tahapan yang dilakukan antara lain menentukan tingkat kepentingan komponen cluster dengan theoritical descriptive analysis, kemudian menyusun kriteria pembentukan cluster dan membentuk cluster ODTW dengan mengelaborasi hasil theoritical descriptive analysis dan karakteristik eksisting ODTW Kota Yogyakarta yang didapatkan dari empirical descriptive analysis. Berdasarkan hasil analisis, dari 21 ODTW Kota Yogyakarta, terbentuk 5 cluster ODTW di Kota Yogyakarta yang selanjutnya akan menjadi input dalam peningkatan integrasi antar ODTW Kota Yogyakarta.
\end{abstract}

Kata Kunci-Objek Daya Tarik Wisata, Cluster ODTW, Kota Yogyakarta

\section{PENDAHULUAN}

I NDONESIA merupakan salah satu negara berkembang dengan potensi dalam pariwisatanya yaitu alam, seni, dan budaya yang menjadi tujuan wisatawan. Unsur yang membedakan pariwisata Indonesia dengan pariwisata negara lain terletak pada budaya dan masyarakatnya. Setiap wilayah maupun suku di Indonesia memiliki keanekaragaman budaya dan keramahtamahan (hospitality services), sehingga mampu menarik wisatawan lebih banyak, terutama wisatawan mancanegara. Hal ini dapat dilihat dari jumlah kunjungan wisatawan mancanegara ke Indonesia pada tahun 2013 meningkat 7,3\% dibanding tahun 2012 [1].

Kota Yogyakarta sebagai salah satu pusat kebudayaan di Pulau Jawa memiliki potensi pariwisata yang beragam, yaitu seni, budaya, dan tatanan kehidupan masyarakat setempat.
Hingga Bulan Mei 2013, jumlah kunjungan wisatawan mancanegara ke Kota Yogyakarta mengalami kenaikan hingga 42,21\% dibandingkan pada tahun 2012 [2]. Hal ini juga mempengaruhi pendapatan per kapita Kota Yogyakarta yaitu sebesar Rp 33,2 juta per tahun dan jauh diatas pendapatan per kapita Provinsi DIY yaitu Rp 14,85 juta per tahun [3].

Namun disisi lain, terdapat beberapa permasalahan yang dihadapi dalam pengembangan pariwisata Kota Yogyakarta, meskipun telah dilakukan berbagai upaya dalam meningkatkan angka kunjungan wisatawan mancanegara. Salah satu masalah tersebut adalah distribusi kunjungan wisatawan yang kurang merata antara Objek Daya Tarik Wisata (selanjutnya disebut ODTW) di pusat dan pinggir kota. Hal tersebut ditunjukkan dengan terjadinya penumpukan kegiatan pariwisata di pusat kota yaitu Jalan Malioboro dan sekitarnya. Penumpukan kegiatan pariwisata dapat dilihat berdasarkan perbandingan kunjungan wisatawan mancanegara, dimana jumlah kunjungan Kraton Yogyakarta yang terletak di pusat kota selama tahun 2012 adalah sebanyak 116.406 orang, sedangkan jumlah kunjungan Museum Sasana Wiratama yang terletak di barat kota hanya berjumlah 30 orang [4]. Oleh sebab itu, diperlukan upaya pemerataan kunjungan wisatawan mancanegara yang salah satunya dapat dilakukan melalui integrasi ODTW.

Integrasi ODTW merupakan konsep totalitas produk wisata yang saling terkait untuk meningkatkan daya saing tiap cluster pariwisata, sehingga terjadi aglomerasi ekonomi serta memudahkan promosi pariwisata. Artikel ini merupakan salah satu tahapan dalam penerapan konsep integrasi ODTW di Kota Yogyakarta, dimana dalam artikel ini akan dibahas lebih lanjut mengenai pembentukan cluster ODTW yang merupakan salah satu proses awal dan dijadikan sebagai input dalam menyusun arahan peningkatan integrasi antar ODTW Kota Yogyakarta. Adapun ODTW yang dimaksud adalah 21 ODTW Kota Yogyakarta yang termasuk dalam tipologi nature tourism, culture tourism, dan kampung wisata.

\section{METODE PENELITIAN}

\section{A. Kajian Pustaka}

Sebelum melakukan proses analisis dalam mebentuk cluster ODTW Kota Yogyakarta, terlebih dahulu ditentukan 
komponen pembentuk cluster yang didapatkan melalui proses kajian pustaka dari [5]-[9]. Berdasarkan hasil kajian pustaka, integrasi ODTW didahului oleh pembentukan keterpaduan secara fisik atau cluster ODTW. Variabel yang didapatkan sebagai komponen pembentuk cluster antara lain diukur melalui kedekatan geografis, kondisi jalan penghubung, moda transportasi penghubung, dan diferensiasi atraksi ODTW.

\section{B. Metode Pengumpulan Data}

Proses pengumpulan data dilakukan melalui survei primer dan survei sekunder. Survei primer merupakan metode pengumpulan data secara langsung untuk mendapatkan karakteristik masing-masing komponen pembentuk cluster yang dilakukan melalui observasi lapangan dan wawancara semi terstruktur dengan pengelola ODTW Kota Yogyakarta. Sedangkan survei sekunder dilakukan melalui survei instansional ke instansi terkait dan survei literatur dari buku, peraturan dan kebijakan terkait, serta hasil penelitian terdahulu sebagai bahan theoritical descriptive analysis. Adapun daftar ODTW Kota Yogyakarta dapat dilihat pada tabel berikut.

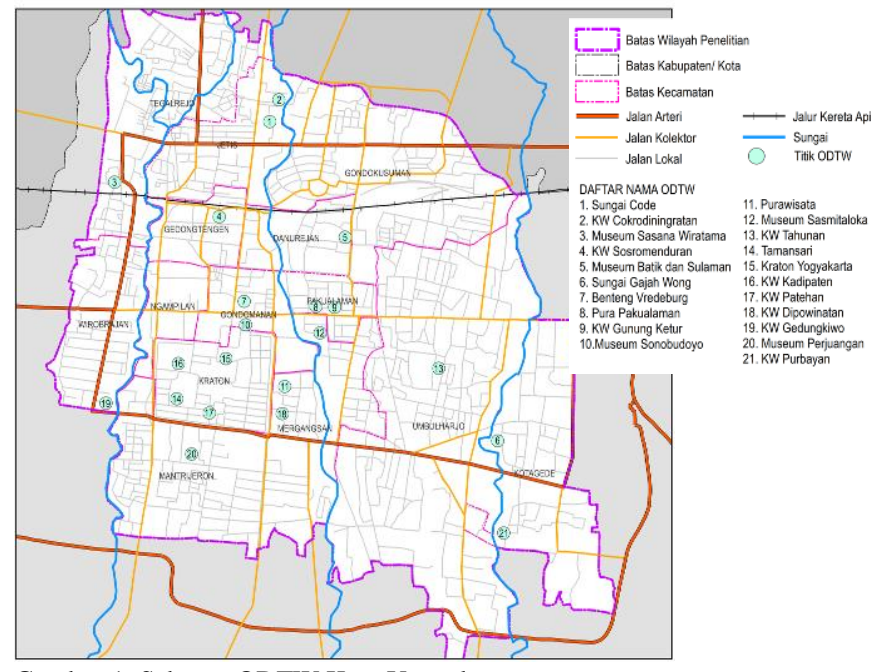

Gambar 1. Sebaran ODTW Kota Yogyakarta

\section{Metode Analisis Data}

Dalam membentuk cluster ODTW Kota Yogyakarta, komponen cluster ODTW yang didapatkan melalui kajian pustaka selanjutnya dianalisis sesuai tahapan analisis. Tahapan tersebut antara lain menentukan tingkat kepentingan komponen cluster ODTW, menyusun kriteria pembentukan cluster ODTW, dan membentuk cluster ODTW. Penentuan tingkat kepentingan komponen bertujuan untuk mengetahui komponen mana yang lebih penting dari komponen lainnya sebagai input dalam poses penggabungan peta individu untuk menghasilkan cluster ODTW. Kemudian dilakukan penyusunan kriteria pembentukan cluster yang merupakan penjabaran spesifik dari komponen cluster ODTW dan merupakan dasar dalam pembentukan cluster. Dalam membentuk cluster, dilakukan elaborasi hasil karakteristik di lapangan yang disesuaikan dengan kriteria yang telah disusun. Analisis dilanjutkan dengan proses penggabungan atau penampalan peta individu hasil kriteria untuk menghasilkan peta ODTW yang memiliki hubungan keterkaitan sehingga membentuk cluster ODTW. Metode analisis yang digunakan antara lain sebagai berikut:

\section{Empirical Descriptive Analyis}

Empirical descriptive analysis merupakan analisis dalam melakukan identifikasi secara intensif terhadap perilaku, karakteristik, maupun data eksisting lainnya yang jika dikompilasikan akan dapat menjawab tujuan penelitian. Dalam hal ini, empirical descriptive analysis dilakukan untuk mendapatkan karakteristik masing-masing komponen cluster ODTW sebagai bahan komparasi dalam analisis penyusunan kriteria pembentukan cluster dan analisis pembentukan cluster ODTW. Empirical descriptive analysis kemudian diperkuat dengan theoritical descriptive analysis.

\section{Theoritical Descriptive Analysis}

Theoritical descriptive analysis merupakan analisis yang dilakukan dengan membandingkan antara kondisi eksisting di lapangan dengan teori, kebijakan, serta hasil penelitian terkait. Proses theoritical descriptive analysis terlebih dahulu digunakan untuk menentukan tingkat kepentingan komponen cluster ODTW. Kemudian, metode ini juga dilakukan dalam penyusunan kriteria pembentukan cluster ODTW untuk memperkuat hasil kondisi eksisting di lapangan.

\section{HASIL DAN DISKUSI}

\section{A. Analisis Penentuan Tingkat Kepentingan Komponen Cluster ODTW Kota Yogyakarta}

Analisis ini dimaksudkan untuk mengukur tingkat kepentingan komponen cluster ODTW dalam melakukan pembentukan cluster. Teknik analisis yang digunakan adalah theoritical descriptive analysis. Proses komparasi dalam analisis ini dilakukan dengan membandingkan teori, kebijakan, dan penelitian serupa terkait komponen integrasi pariwisata, kemudian disesuaikan untuk masing-masing komponen. Penilaian tingkat kepentingan komponen ditampilkan dalam bentuk skala ordinal dan disusun berdasarkan ranking tertinggi sampai terendah, yaitu skor 4 untuk komponen tingkat kepentingan sangat tinggi sebagai penentu dasar pembentukan cluster; skor 3 untuk komponen tingkat kepentingan tinggi dalam pembentukan cluster; skor 2 untuk komponen tingkat kepentingan sedang dalam pembentukan cluster; serta skor 1 untuk komponen dengan tingkat kepentingan rendah dalam pembentukan cluster.

Dari hasil analisis, didapatkan bahwa komponen paling berpengaruh adalah komponen terkait kemudahan pencapaian ODTW. Komponen penentu dasar dengan tingkat kepentingan sangat tinggi adalah kedekatan geografis dengan skor 4 . Kedekatan geografis (jarak) dapat memberikan efisiensi dalam waktu pencapaian, pengelolaan, upaya promosi, dan hubungan antar stakeholder terkait. Selanjutnya diidentifikasi kondisi jalan penghubung antar ODTW yang dapat berpengaruh terhadap waktu tempuh pencapaian ODTW dengan skor 3. Kemudian moda transportasi penghubung memiliki skor 2 
untuk mengukur ketersediaan moda transportasi umum yang menghubungkan antar ODTW. Sedangkan komponen lain terkait pembentukan cluster namun tidak terkait dengan kemudahan pencapaian adalah diferensiasi atraksi ODTW dengan skor 1 sebagai bentuk diversifikasi dan variasi ODTW, sehingga dapat memperkuat karakteristik cluster.

\section{B. Analisis Penyusunan Kriteria Pembentukan Cluster ODTW Kota Yogyakarta}

Dalam analisis penyusunan kriteria pembentukan cluster, Kriteria yang dimaksud merupakan batasan spesifik pembentukan cluster ODTW Kota Yogyakarta yang didapatkan dari komponen pembentuk cluster. Untuk menghasilkan kriteria pembentukan cluster ODTW Kota Yogyakarta, kondisi eksisting komponen cluster ODTW dibandingkan dengan bahan komparasi melalui theoritical descriptive analysis. Bahan komparasi tersebut antara lain berupa teori, kebijakan, serta penelitian terdahulu yang kemudian dikaitkan dengan penelitian dan kondisi eksisting di lapangan sehingga dapat menghasilkan kriteria spesifik sesuai karakteristik komponen cluster ODTW Kota Yogyakarta.

Pada komponen kedekatan geografis, Kota Yogyakarta termasuk dalam perkotaan kecil dengan luas $32,5 \mathrm{~km}^{2}$, sehingga pencapaian antar ODTW berdasarkan panjang jalan penghubung cukup dekat dengan range $2-4 \mathrm{~km}$. Untuk kondisi jalan penghubung, permasalahan transportasi yang menghambat pergerakan kendaraan di Kota Yogyakarta antara lain kemacetan, jalan satu arah, serta kondisi permukaan jalan yang buruk. Kemudian untuk moda transportasi penghubung, jenis moda transportasi yang digunakan di Kota Yogyakarta adalah Bus Trans Jogja yang melayani hampir seluruh ODTW. ODTW dapat diakses dengan berjalan kaki sejauh $100-400$ $\mathrm{m}$ dari halte pemberhentian bus. Sedangkan untuk diferensiasi atraksi ODTW, ODTW Kota Yogyakarta terbagi menjadi 3 jenis dan umumnya memiliki paket wisata pada ODTW yang terletak berdekatan. Selain itu, kampung wisata di Kota Yogyakarta merupakan alternatif atraksi untuk mendukung ODTW baik culture maupun nature tourism didekatnya.

Berdasarkan hasil analisis, didapatkan hasil spesifikasi komponen cluster yang digunakan sebagai kriteria pembentukan cluster ODTW Kota Yogyakarta. Adapun kriteria-kriteria tersebut berdasarkan tingkat kepentingannya adalah sebagai berikut:

1. Kriteria untuk kedekatan geografis:

Kedekatan jarak antar ODTW berdasarkan panjang jalan penghubung yang dapat ditempuh oleh pedestrian dengan range maksimum $2 \mathrm{~km}$, serta tingkat keterkaitan antara lain (a) Jarak $<1 \mathrm{~km}$ memiliki keterkaitan kuat dan merupakan prioritas cluster; (b) Jarak $1-1,5 \mathrm{~km}$ memiliki keterkaitan sedang; (c) Jarak 1,5 - $2 \mathrm{~km}$ memiliki keterkaitan lemah.

2. Kriteria untuk kondisi jalan penghubung:

Kondisi jalan penghubung antar ODTW dengan jarak minimum $1-2 \mathrm{~km}$ yang tidak mengalami permasalahan terkait lamanya waktu tempuh dalam pencapaian satu sama lain. Permasalahan tersebut antara lain kemacetan, adanya jalan satu arah, serta kondisi permukaan jalan yang buruk.

3. Kriteria untuk moda transportasi penghubung:

Jarak pencapaian halte pemberhentian Bus Trans Jogja dengan ODTW yang dapat ditempuh oleh pedestrian dengan jarak maksimum $400 \mathrm{~m}$, serta ODTW yang dilewati oleh jalur Bus Trans Jogja yang sama dan tidak dicapai dengan pergantian jalur.

4. Kriteria untuk diferensiasi atraksi ODTW:

ODTW (nature atau culture tourism) dan kampung wisata yang diarahkan sebagai objek utama dan kampung wisata pendukungnya, serta tergabung dalam 1 (satu) paket promosi atau paket wisata.

\section{Analisis Pembentukan Cluster ODTW Kota Yogyakarta}

Dari kriteria yang telah disusun dalam analisis sebelumnya, dilakukan penyesuaian antara kondisi eksisting dan kriteria sebagai dasar penggabungan peta hasil kriteria dalam membentuk cluster ODTW Kota Yogyakarta. Berdasarkan kriteria untuk kedekatan geografis, didapatkan hasil analisis keterkaitan jarak antar ODTW yang menunjukkan bahwa terdapat 57 hubungan keterkaitan antar ODTW Kota Yogyakarta dengan rincian sebagai berikut:

1. ODTW yang memiliki keterkaitan kuat dan merupakan prioritas cluster teridentifikasi sebanyak 11 hubungan, ditunjukkan dari panjang jalan penghubung antar ODTW-nya yang berjarak kurang dari $1 \mathrm{~km}$;

2. ODTW yang memiliki keterkaitan sedang teridentifikasi sebanyak 18 hubungan, ditunjukkan dari panjang jalan penghubung antar ODTW-nya yang berjarak antara $1 \mathrm{~km}$ hingga $1,5 \mathrm{~km}$;

3. Sedangkan ODTW yang memiliki keterkaitan lemah teridentifikasi sebanyak 28 hubungan, ditunjukkan dari panjang jalan penghubung antar ODTW-nya yang berjarak antara $1,5 \mathrm{~km}$ sampai $2 \mathrm{~km}$

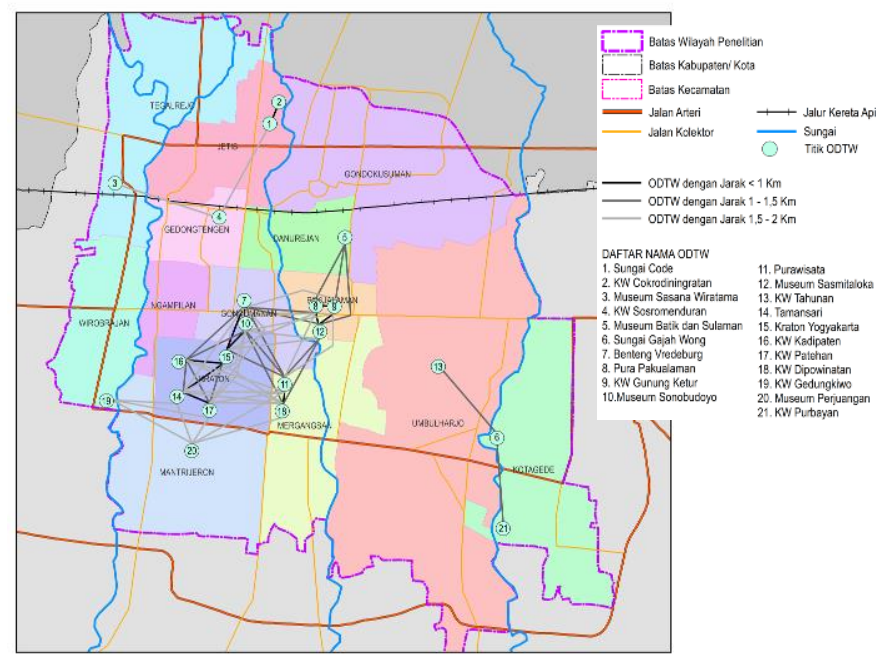

Gambar 2. Keterkaitan ODTW Berdasarkan Kedekatan Geografis

Berdasarkan kriteria untuk kondisi jalan penghubung, didapatkan 12 hubungan antar ODTW yang tidak memiliki permasalahan transportasi, serta 9 hubungan ODTW yang dapat dicapai dengan berjalan kaki karena letaknya yang 
dalam 1 kompleks dan terdapat parkir terpusat untuk mendukung wisatawan dalam berjalan kaki antar 1 ODTW ke ODTW lainnya. Kompleks tersebut adalah Museum Sonobudoyo, Kraton Yogyakarta, Tamansari, Kampung Wisata Patehan, dan Kampung Wisata Kadipaten. Secara keseluruhan, terdapat 21 dari total 46 hubungan ODTW yang memiliki keterkaitan berdasarkan kondisi jalan penghubungnya.

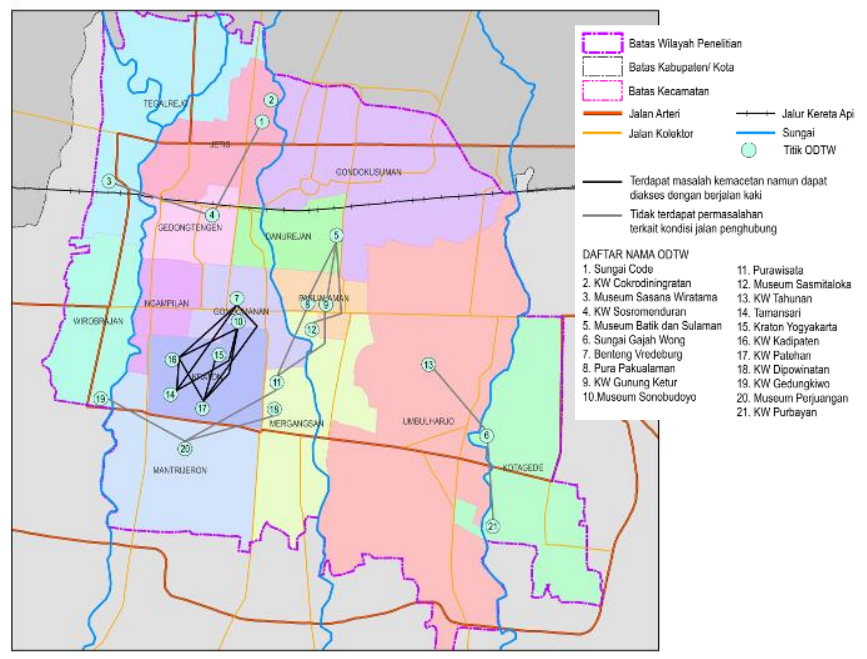

Gambar 3. Keterkaitan ODTW Berdasarkan Kondisi Jalan Penghubung

Sedangkan hasil analisis kesamaan jalur Bus Trans Jogja antar ODTW menunjukkan bahwa terdapat beberapa ODTW yang memiliki jarak lebih dari 400 meter untuk mencapai halte pemberhentian Bus Trans Jogja terdekat, yaitu Museum Sasana Wiratama, Kraton Yogyakarta, Tamansari, Kampung Wisata Kadipaten, dan Kampung Wisata Patehan. Dari komponen ini diketahui bahwa terdapat 14 hubungan ODTW yang memiliki keterkaitan dari moda transportasi penghubungnya.

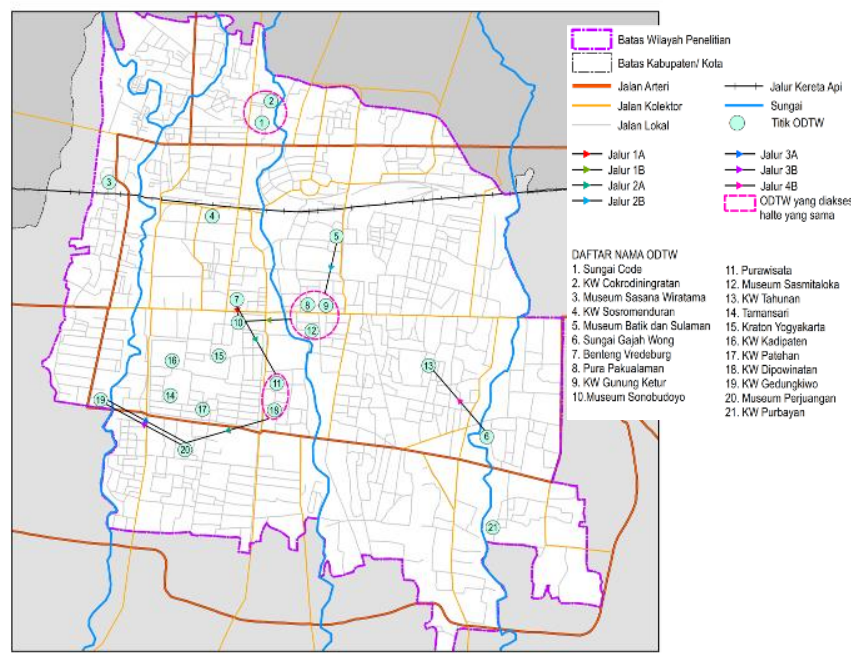

Gambar 4. Keterkaitan ODTW Berdasarkan Kesamaan Jalur Bus Trans Jogja

Untuk komponen terakhir yaitu diferensiasi atraksi ODTW, hasil analisis menunjukkan bahwa terdapat 6 hubungan ODTW yang merupakan ODTW dengan kampung wisata pendukungnya, serta terdapat 21 hubungan ODTW yang termasuk dalam paket promosi/ wisata yang sama. Secara keseluruhan, dari total 57 hubungan yang ada, terdapat 21 hubungan ODTW yang memiliki keterkaitan berdasarkan diferensiasi atraksi ODTW-nya.

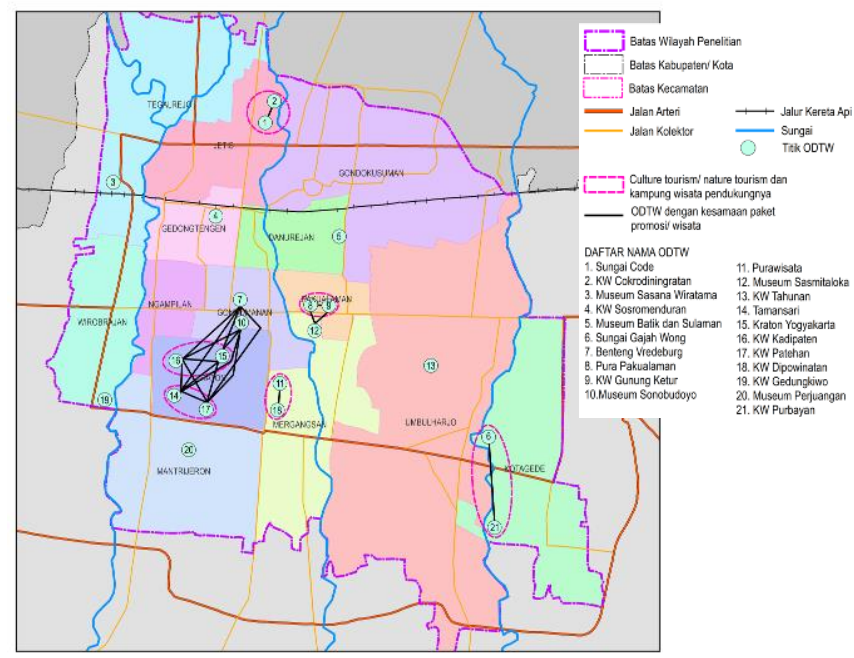

Gambar 5. Keterkaitan ODTW Berdasarkan Diferensiasi Atraksi ODTW

Hasil analisis dari kriteria-kriteria tersebut diatas kemudian digabungkan untuk menemukan hasil cluster ODTW Kota Yogyakarta. Proses yang dimaksud merupakan proses pendekatan yang dibentuk dari penggabungan beberapa peta individu dengan karakteristik yang sama, yaitu memiliki keterkaitan antar ODTW-nya, yang digunakan untuk menampalkan peta sehingga menghasikan peta gabungan yang memiliki seluruh informasi/ atribut dari peta-peta tersebut. Proses penggabungan peta hasil kriteria untuk membentuk cluster ODTW dapat dilihat pada gambar berikut.

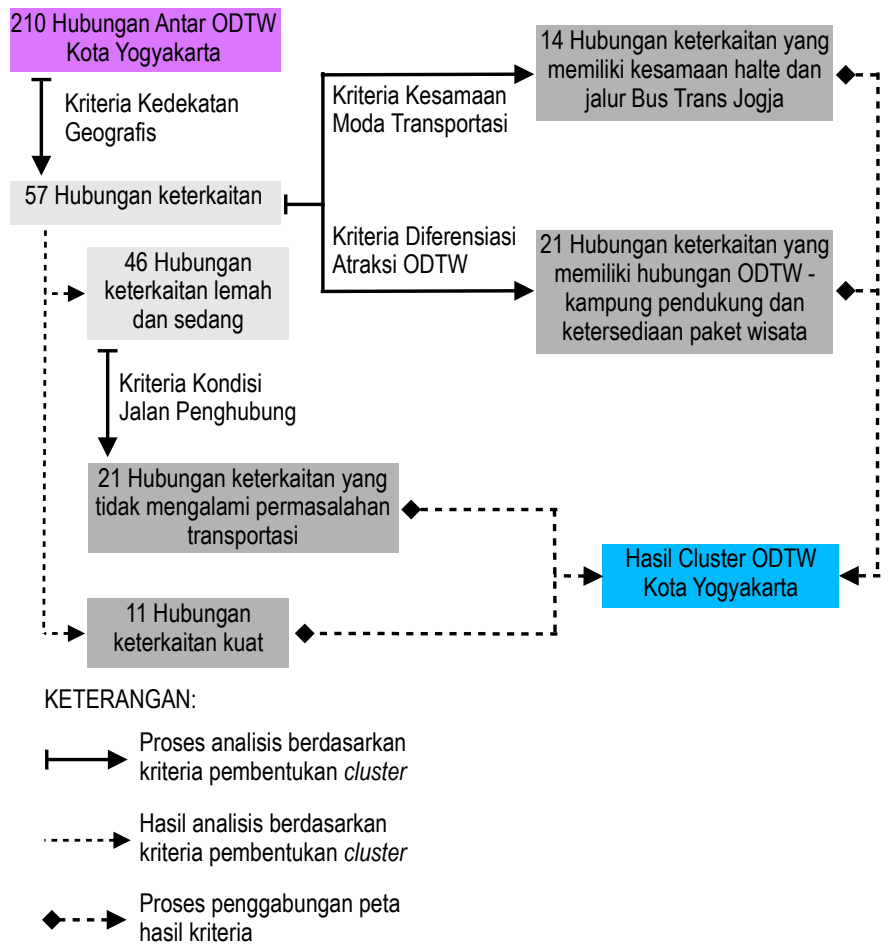

Gambar 6. Proses Penggabungan Peta Kriteria dalam Membentuk Cluster ODTW Kota Yogyakarta 
Adapun hasil akhir cluster ODTW Kota Yogyakarta yang terbentuk berdasarkan kriteria pembentukan cluster-nya dapat dilihat sebagai berikut, dimana penentuan delineasi batas cluster ODTW dibentuk secara dinamis dengan tidak mengikuti batas administratif wilayah.

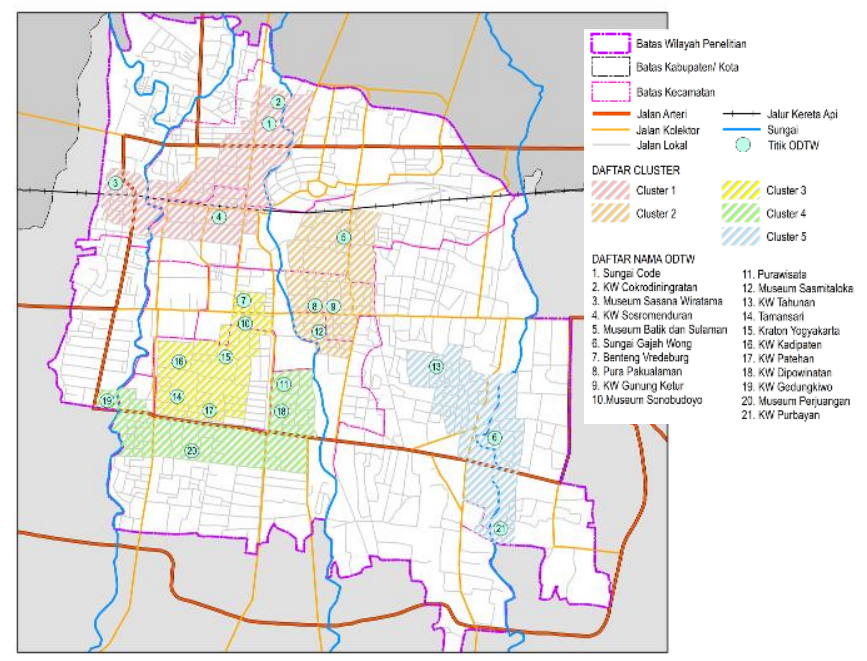

Gambar 7. Hasil Cluster ODTW Kota Yogyakarta

\section{KESIMPULAN}

Pembentukan cluster ODTW Kota Yogyakarta dilakukan sebagai salah satu proses peningkatan integrasi antar ODTW dalam rangka pemerataan kunjungan wisatawan mancanegara antar ODTW di pusat dan pinggir Kota Yogyakarta. Komponen pembentuk cluster ODTW terdiri dari komponen keterpaduan fisik dengan urutan tingkat kepentingan dari tinggi sampai rendah berturut-turut adalah kedekatan geografis, kondisi jalan penghubung, moda transportasi penghubung, dan diferensiasi atraksi ODTW.

Berdasarkan hasil elaborasi antara kondisi eksisting komponen pembentukan cluster dan teori, didapatkan kriteria pembentukan cluster ODTW Kota Yogyakarta yang spesifik sesuai karakteristik komponen pembentuk cluster di lapangan. Kriteria tersebut kemudian digunakan untuk menganalisis hubungan keterkaitan antar ODTW sebagai dasar pembentukan cluster ODTW. Adapun dari 21 ODTW Kota Yogyakarta, dihasilkan 5 cluster ODTW Kota Yogyakarta berdasarkan proses penggabungan peta hasil kriteria. Cluster tersebut antara lain:

a. Cluster 1 terdiri dari Sungai Code, Kampung Wisata Cokrodiningratan, Museum Sasana Wiratama, dan Kampung Wisata Sosromenduran;

b. Cluster 2 terdiri dari Museum Batik dan Sulaman, Pura Pakualaman, Kampung Wisata Gunung Ketur, dan Museum Sasmitaloka;

c. Cluster 3 terdiri dari Benteng Vredeburg, Museum Sonobudoyo, Tamansari, Kraton Yogyakarta, Kampung Wisata Kadipaten, dan Kampung Wisata Patehan;

d. Cluster 4 terdiri dari Purawisata, Kampung Wisata Dipowinatan, Kampung Wisata Gedungkiwo, dan Museum Perjuangan; e. Cluster 5 terdiri dari Sungai Gajah Wong, Kampung Wisata Tahunan, dan Kampung Wisata Purbayan.

\section{DAFTAR PUSTAKA}

[1] Republika.co.id. 2013. Kontribusi Pariwisata terhadap Pertumbuhan Ekonomi Indonesia Meningkat. diakses tanggal 11 Maret 2014 pukul $20.00 \mathrm{WIB}$.

[2] Jateng.bps.go.id. Berita Resmi Statistik No. 43/07/Th. XVI. diakses tanggal 11 Maret 2014 pukul 20.00 WIB.

[3] Badan Pusat Statistik Kota Yogyakarta. 2012. Statistik Daerah Kota Yogyakarta 2012. Yogyakarta: Badan Pusat Statistik Kota Yogyakarta.

[4] Dinas Pariwisata Daerah Istimewa Yogyakarta. 2013. Statistik Kepariwisataan Provinsi DIY. Yogyakarta: Dinas Pariwisata Daerah Istimewa Yogyakarta.

[5] Porter, M. 1998. Clusters and The New Economics of Competition. Jurnal Harvard Business Review Volume 76 nomor 6 Tahun 1998.

[6] Ferreira, Joao, dan Cristina Estevao. 2009. Regional Competitivensess of Tourism Cluster: A Conceptual Model Proposal. Portugal: University of Beira Interior.

[7] Nordin, Sara. 2003. Tourism Clustering and Innovation. Sweden: European Tourism Research Institute Mid-Sweden University.

[8] Utama, I Gusti Bagus Rai. 2013. Pengembangan Wisata Kota sebagai Masa Depan Indonesia.

[9] Postma, Albert. 2002. An Approach for Integrated Development of Quality Tourism. Dublin: Dublin Institute of Technology. 